\title{
Effects of $n$-butanol presence, inlet loading, empty bed residence time and starvation periods on the performance of a biotrickling filter removing cyclohexane vapors from air
}

\author{
Piotr Rybarczyk ${ }^{1}$ (D) - Bartosz Szulczyński ${ }^{1} \cdot$ Milena Gospodarek $^{1} \cdot J_{a c e k}$ Gębicki ${ }^{1}$
}

Received: 30 June 2019 / Accepted: 21 September 2019 / Published online: 3 October 2019

(c) The Author(s) 2019

\begin{abstract}
This paper presents the results of investigations on the removal of cyclohexane vapors from air using a peat-perlite packed biotrickling filter. Effects of basic process parameters i.e. inlet loading and empty bed residence time as well as introduction of $n$-butanol to the treated air stream and starvation periods on the process performance were evaluated. The results show that the introduction of hydrophilic $n$-butanol results in an enhanced removal of hydrophobic cyclohexane comparing to the experiments where only cyclohexane was treated. Additionally, the biotrickling filter performance after the starvation events is regained to more extent for mixed system than for the single cyclohexane. A novel and interesting element of the paper is the application of an electronic nose for the process monitoring. Obtained results are discussed in the perspective of an influence of the presence of a compound with different affinity to aqueous phase on the removal efficiency of the compound with opposite chemical properties.
\end{abstract}

Keywords Biofiltration $\cdot$ Biotrickling filter $\cdot$ Cyclohexane $\cdot n$-Butanol $\cdot$ Removal of VOCs $\cdot$ Electronic nose

$\begin{array}{ll}\text { List of symbols } \\ a & \text { Coefficient of MLR model } \\ B & \text { Boiling point }\left({ }^{\circ} \mathrm{C}\right) \\ \text { BF } & \text { Biotrickling filter } \\ \text { BTF } & \text { Biotrickling filtration } \\ c & \text { Concentration of cyclohexane in the gas mixture } \\ & \text { (ppm v/v) } \\ C & \text { Concentration of cyclohexane in the gas mixture } \\ & \left.\text { (mg m }{ }^{-3}\right) \\ d & \text { Internal diameter of BTF }\left(\mathrm{m}^{3}\right) \\ \text { EC } & \text { Elimination capacity }\left(\mathrm{g} \mathrm{m}^{-3} \mathrm{~h}^{-1}\right) \\ \mathrm{EBRT} & \text { Empty bed residence time s } \\ \mathrm{GC} & \text { Gas chromatography } \\ h & \text { Total height of a BTF packing }(\mathrm{m}) \\ H & \text { Henry’s constant }\left(\mathrm{mol} \mathrm{m}^{-3} \mathrm{~Pa}^{-1}\right)\end{array}$

This work was presented at the 44th International Conference of Slovak Society of Chemical Engineering held in Tatranské Matliare on May 21-25, 2018.

Piotr Rybarczyk

piotr.rybarczyk@pg.edu.pl

1 Department of Process Engineering and Chemical Technology, Gdańsk University of Technology, Faculty of Chemistry, Narutowicza 11/12 Street, 80-233 Gdańsk, Poland

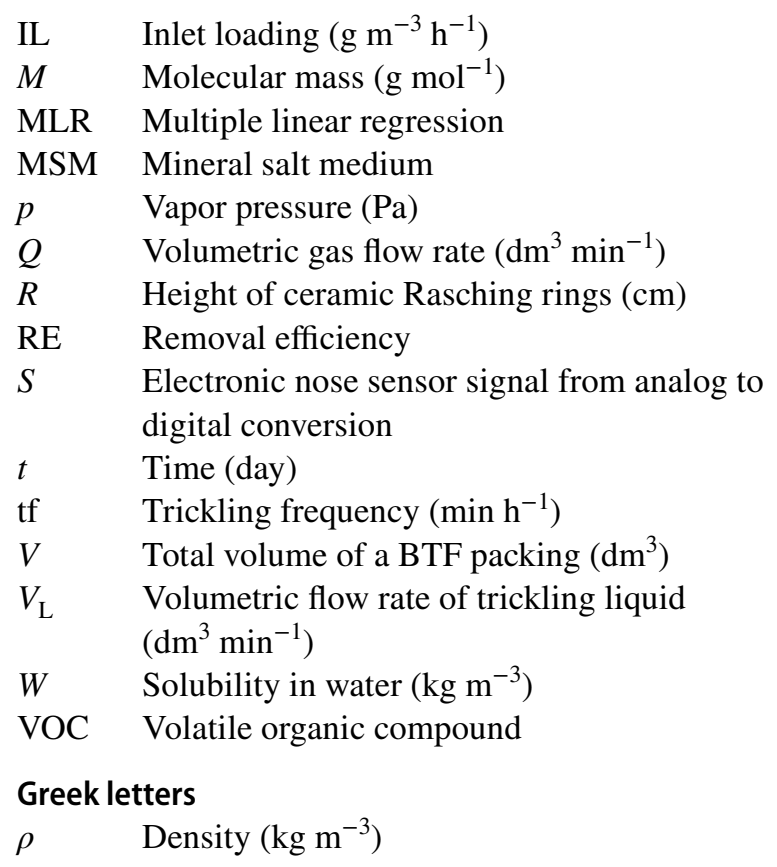

\section{Subscripts}

b Bottom layer of Raschig rings

$\mathrm{t} \quad$ Top layer of Raschig rings

in Inlet gas stream

out Outlet gas stream 


\section{Introduction}

Efficient and cost-effective removal of malodorous gases from air is raising in importance from both social and environmental issues. Among various treatment methods for air deodorization (e.g. absorption, adsorption, thermal oxidation), biological processes, including biofiltration, are favored due to high efficiency, low operational costs and minute secondary pollution (McNevin and Barford 2000; Mudliar et al. 2010; Gospodarek et al. 2019). Biotrickling filtration (BTF) is a specific mode of biofiltration, combining the features of biofilters and bioscrubbers in one apparatus. The process of biotrickling filtration consists in passing an odorous gas through a packed bed, trickled with a liquid enriched with mineral salts. A biofilm containing microorganisms is developed on the elements of a packing material. As a result of mass transfer of gas components to the biofilm, the concentration of the pollutants in the gas phase decrease and these components, absorbed by the biofilm and adsorbed on the surface of packing elements, undergo biodegradation (Schiavon et al. 2016).

Due to the construction pattern of biotrickling filters (BF), hydrophilic volatile organic compounds (VOCs) are generally easily removed from air due to their relatively high water-solubility and bioavailability. In such a case, the removal performance of the biofilter is limited by the reaction rate. However, when hydrophobic VOCs are treated, the limitation step of the process is the diffusion from the gas phase to the aqueous biofilm. Thus, the removal efficiencies of hydrophobic compounds are lower than for hydrophilic compounds (Cheng et al. 2016a; Yang et al. 2018).

The performance of biotrickling filters is basically dependent on following elements: composition of the feed gas, applied packing material, inlet loading, gas flow rate, temperature, composition of the biofilm, composition of liquid and frequency of trickling the filter bed, but also on the starvation periods and shock loads of pollutants (Mirmohammadi et al. 2014; Jiménez et al. 2017; Barbusinski et al. 2017; Rybarczyk et al. 2019). The research on biotrickling filtration has been mainly focused on the removal of single pollutants from air. For example, Montebello et al. (2013) investigated effects of packing materials and $\mathrm{pH}$ on the performance and microbial diversity of $\mathrm{BF}$ treating hydrogen sulfide. Lebrero et al. investigated the mass transfer of toluene in polyurethane-packed BF (Lebrero et al. 2012). Influence of addition of an organic phase to the trickling liquid was investigated for the biotrickling filtration of $\alpha$-pinene (Montes et al. 2010). Effects of empty bed residence time and inlet loading on the steadystate operated BF treating chlorobenzene were investigated by Yang et al. (2013).

Currently, the development of biofiltration techniques, including biotrickling filtration, concentrates, among others, on the enhancement methods of the removal of hydrophobic VOCs. This may be realized by several approaches, e.g. use of surfactants (Yang et al. 2010a; Song et al. 2012; Tu et al. 2015; Cheng et al. 2016b; Qian et al. 2018), reactor modification (Chen et al. 2012; Muñoz et al. 2012), selection of microbial species (Rene et al. 2010). Interestingly, research indicates that the removal of hydrophobic compounds may be improved when hydrophilic compounds are introduced to the treated gas stream. Such an approach allows for mixing various streams of gases to enhance the overall removal rate. Yang et al. (2018) analyzed the simultaneous removal of multi-component VOCs in conventional biofilters pointing out that positive, negative or neutral interactions between substrates may occur. Such interactions lead to either enhanced or decreased efficiency of the process. This may be a result of changes in the bioavailability and biodegradability of the target compounds when mixtures of VOCs with different affinity to aqueous phase are considered.

Selection of cyclohexane and $n$-butanol as objectives of this study results from their different physicochemical properties, as presented in Table 1. Cyclohexane is characterized by very low value of Henry's constant $(H)$ as well as low solubility in water, thus indicating its hydrophobic character. Contrary, both $H$ value and solubility in water for hydrophilic $n$-butanol are several orders of magnitude higher than for cyclohexane. Additionally, these compounds have been very rarely studied as target compounds for biotrickling filtration.

In this paper, as a packing material was used a mixture of peat and perlite sandwiched between bottom and upper layers of Raschig rings. It is worth noting that natural media are inhabited by plenty of microorganisms and does not require inoculation prior to the biofilter's startup. However, due to

Table 1 Selected physicochemical parameters of cyclohexane and $n$-butanol (Japan Chemical Industry Ecology-Toxicology \& Information Center 1992; Yalkowsky and He 2010)

\begin{tabular}{lllllll}
\hline Compound & $M\left(\mathrm{~g} \mathrm{~mol}^{-1}\right)$ & $\rho\left(\mathrm{kg} \mathrm{m}^{-3}\right)$ & $p(\mathrm{~Pa})$ & $H\left(\mathrm{~mol} \mathrm{~m}^{-3} \mathrm{~Pa}^{-1}\right)$ & $W\left(\mathrm{~kg} \mathrm{~m}^{-3}\right)$ & $B\left({ }^{\circ} \mathrm{C}\right)$ \\
\hline Cyclohexane & 84 & 780 & 13,200 & $5.3 \times 10^{-5}$ & 0.055 & 81 \\
$n$-Butanol & 78 & 810 & 995 & 1.1 & 68 & 117 \\
\hline
\end{tabular}

$M$ molecular mass, $\rho$ density, $p$ vapor pressure, $W$ solubility in water, $B$ boiling point 
the limited stability and need of relatively frequent exchange, natural packing materials are usually applied in conventional biofilters rather than in biotrickling filters (Barbusinski et al. 2017; Wu et al. 2018). Interestingly, the research is proposed on the application of such media in biotrickling filters $(\mathrm{Wu}$ et al. 2018; Szulczyński et al. 2019). In such a case, natural media are usually mixed with inert materials (e.g. ceramics) to limit the bed clogging as well as excessive pressure drop and shorter biofilter start-up periods are possible comparing to typical periods of biotrickling filter's start up after the inoculation of the packing material.

Peat is exceptionally interesting as a biofilter packing material because it is naturally inhabited by plenty of microbial species, thus giving the possibility for the efficient removal of a broad scope of volatile organic compounds from air. For example, more than 600 fungi species have been isolated from natural peat samples (Thormann and Rice 2007). Thus, isolation and selection of microbial species from peat samples, especially fungal microbes, and subsequent inoculation to BF may serve as a way of enhancing the biofiltration efficiency when hydrophobic VOCs are of interest (Cheng et al. 2016a, b, c; Rybarczyk et al. 2019).

Recently, the first research on biotrickling filtration of cyclohexane was presented by Salamanca et al. (2017). It was found that the removal efficiency of cyclohexane was within the range $80-99 \%$, corresponding to the elimination capacity (EC) of up to $38 \mathrm{~g} \mathrm{~m}^{-3} \mathrm{~h}^{-1}$, in the biotricklng filter packed with polyurethane foam, inoculated with Acidovorax sp. CHX 100. Biotrickling filtration of $n$-butanol was investigated by Schmidt et al., indicating high removal efficiency of $n$-butanol for the inlet concentrations in the range of $1-2.5 \mathrm{~g} \mathrm{~m}^{-3}$ (Schmidt et al. 2017), resulting in the maximum values of EC reaching $100 \mathrm{~g} \mathrm{~m}^{-3} \mathrm{~h}^{-1}$. Up to the best knowledge of the authors of this manuscript, no paper is available on the evaluation of the influence of $n$-butanol on the performance and removal efficiency of BF treating cyclohexane. Additionally, typically for the investigations of laboratory biotrickling filtration processes, the results are evaluated using gas chromatography (GC) technique. From both quantitative as well as qualitative viewpoints, gas chromatography is the most valuable method for this purpose. However, due to the low cost and short time of a single analysis, electronic noses have become an alternative to gas chromatography in many instances (Szulczyński et al. 2017). The use of an electronic nose allows to monitor the process in an on-line mode and it has been successfully used in the assessment of the biofiltration process efficiency (Cabeza et al. 2013; Guz 2015; Szulczyński et al. 2018). Thus, beside gas chromatography, an electronic nose is used for the evaluation of the process performance in this study.

Taking into account a possible approach of enhancing the removal of hydrophobic VOC in BF, the main aim of this paper is to investigate an influence of addition of a hydrophilic compound ( $n$-butanol)on the performance of a biotrickling filter treating air polluted with cyclohexane (hydrophobic compound). Additionally, effects of basic process parameters (inlet loading, IL, and empty bed residence time, EBRT) as well as starvation events are evaluated.

\section{Experimental}

Investigations were performed in two biotrickling filters working in parallel: one biofilter was treating air containing cyclohexane (Merck, Darmstadt, Germany), the other biofilter treated a mixture of cyclohexane and $n$-butanol $(\mathrm{POCH}$, Gliwice, Poland). Each BTF set-up (Fig. 1) consisted of a two-section plexi glass column packed with a mixture of peat and perlite (Compo Sana, Compo GmbH, Münster, Germany). A mixture of peat and perlite was placed on a bottom layer of ceramic Raschig rings $(10 \times 2.4 \mathrm{~mm})$ and covered with a top layer of finer ceramic Raschig rings $(6 \times 1.5 \mathrm{~mm})$ to ensure uniform distribution of trickling liquid and to limit the bed clogging episodes. The pressure drop across the packed bed was monitored during the experiments. The BF was fed with a gas mixture from the bottom and the packed bed was periodically trickled with a liquid from the biofilter top using a peristaltic pump. Detailed information on the BF dimensions and trickling pattern is given in Table 2.

Mixtures of air with cyclohexane or cyclohexane and $n$-butanol were obtained in a gas mixture generator. Gaseous mixtures were generated by passing the purified and dried air via a porous sinter through liquid $n$-butanol and/or cyclohexane contained in vials. The formed mixture was diluted with a zero air stream to achieve the desired concentrations of VOCs. The gas flow rate was controlled and regulated using a precise mass flow controller (Vögtlin, Aesch, Switzerland). Pressure measurements were made using MPX5010DP sensor (NXP Semiconductors, Eindhoven, Netherlands).

The experiments were conducted without a bed inoculation taking advantage of microorganisms naturally inhabiting the peat. Prior to the introduction of a gas flow through a BF, a conditioning of a packing was introduced. A packed bed was activated using a Buffered Peptone Water medium (Merck, Darmstadt, Germany) by trickling for a period of 4 days. After this period, a trickling liquid was changed into mineral salt medium (MSM) containing following salts dissolved in distilled water: $\mathrm{Na}_{2} \mathrm{HPO}_{4} \times 2 \mathrm{H}_{2} \mathrm{O}, \mathrm{KH}_{2} \mathrm{PO}_{4}, \mathrm{NaCl}$ and $\mathrm{NH}_{4} \mathrm{Cl}$ and the gas flow was introduced to the BTF. All the components of MSM were purchased from $\mathrm{POCH}$ ( $\mathrm{POCH}$, Gliwice, Poland). The mineral salt medium was autoclaved prior to its introduction to the BTF. The processes were carried out at room temperature $\left(23-25^{\circ} \mathrm{C}\right)$.

Samples from the inlet and outlet gas streams were taken to Tedlar bags and the concentration of cyclohexane was determined using Varian CP-3800 gas chromatograph 
Fig. 1 Scheme of an experimental set-up

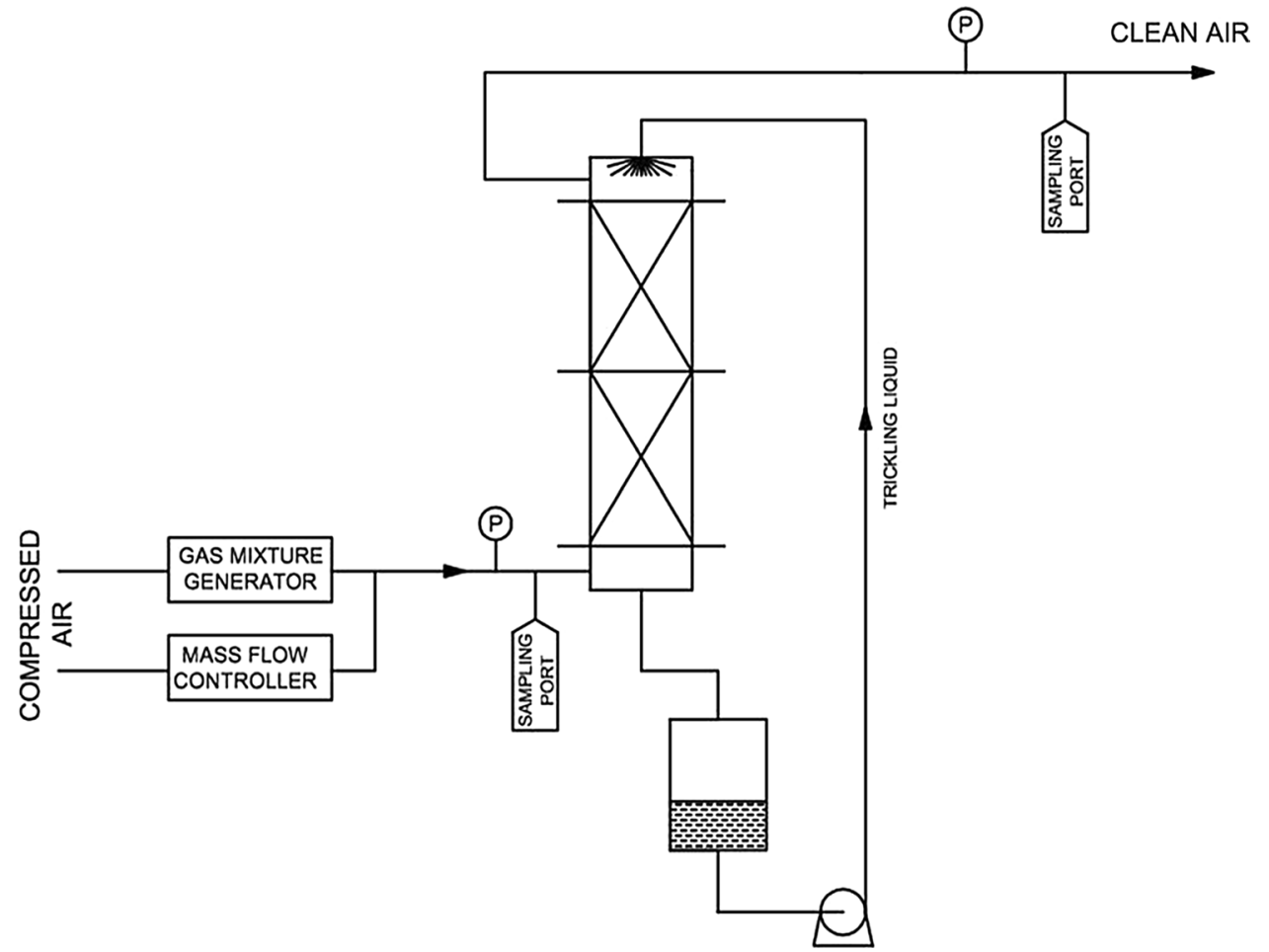

\begin{tabular}{lllllll}
\hline$d(\mathrm{~m})$ & $h(\mathrm{~m})$ & $V\left(\mathrm{dm}^{3}\right)$ & $V_{\mathrm{L}}\left(\mathrm{dm}^{3} \min ^{-1}\right)$ & $\mathrm{tf}\left(\mathrm{min}^{-1}\right)$ & $R_{\mathrm{b}}(\mathrm{cm})$ & $R_{\mathrm{t}}(\mathrm{cm})$ \\
\hline 0.08 & 0.68 & 2.5 & 0.2 & 0.5 & 3 & 2 \\
\hline
\end{tabular}

$d$ internal diameter of BF, $h$ total height of a BF packing, $V$ total volume of a BF packing, $V_{\mathrm{L}}$ volumetric flow rate of trickling liquid, tf trickling frequency, $R_{\mathrm{b}}$ height of bottom layer of Raschig rings, $R_{\mathrm{t}}$ height of top layer of Raschig rings
Table 2 Dimensions of a biotrickling filter and trickling pattern $\log c=a_{0}+a_{1} \times \log S_{1}+a_{2} \times \log S_{2}+\cdots+a_{8} \times \log S_{8}$

Calibration of the electronic nose was carried out in accordance to the previous research (Szulczyński et al. 2018) and after rejecting the statistically insignificant parts of the MLR model (characterized by a determination coefficient equal to 0.91 ) the form of equation is as follows:

$\log c=14.92+0.71 \times \log S_{1}-5.32 \times \log S_{5}$

The process performance and efficiency were evaluated using the values of removal efficiency (RE) and elimination capacity (EC):

$\mathrm{RE}=\frac{C_{\text {in }}-C_{\text {out }}}{C_{\text {in }}} \times 100 \%$

$\mathrm{EC}=\frac{Q\left(C_{\text {in }}-C_{\text {out }}\right)}{V}$

where $C_{\text {in }}$ is the concentration of cyclohexane in the inlet gas stream, $C_{\text {out }}$ is the concentration of cyclohexane in the 
outlet gas stream, $Q$ is the volumetric gas flow rate and $V$ is the total volume of a BTF packing.

Inlet loading as well as empty bed residence time were calculated as follows:

$\mathrm{IL}=\frac{Q \times C_{\text {in }}}{V}$

$\mathrm{EBRT}=\frac{V}{Q}$

\section{Results and discussion}

Effects of IL and EBRT on the removal of cyclohexane from air in the biotrickling filter are presented in Fig. 2. During the first 2 days of a biotrickling filtration process, values of RE increase, reaching maximum value of about $75 \%$, and then the RE values decrease. This may be related to initial absorption and adsorption of cyclohexane in the biofilter packing material, bearing in mind that the microbial flora is not yet sufficiently grown and accommodated to the treated compound. In the second stage of the process, the inlet loading of cyclohexane was increased from 45 to $112.5 \mathrm{~g} \mathrm{~m}^{-3} \mathrm{~h}^{-1}$. This resulted in fluctuations and further decrease of RE values. During the stage III, inlet loading of cyclohexane was decreased to $45 \mathrm{~g} \mathrm{~m}^{-3} \mathrm{~h}^{-1}$ and the values of RE increased, reaching about $85-90 \%$ at the 25 th day of the process. This may indicate the accommodation of the microbial species to the treated gas. A considerable increase of IL at the stage IV (from 45 to $180 \mathrm{~g} \mathrm{~m}^{-3} \mathrm{~h}^{-1}$ ) caused only a slight decrease of RE values, indicating rather a stable behavior of the system to the shock load of cyclohexane. The values of RE stabilize at the level of about $75 \%$, even for increased inlet loading, resulting from a decrease of EBRT at the stage V. Similar pattern of decrease of the VOCs removal efficiency for increased inlet loadings was encountered by Vergara-Fernandez et al. (2018). It may be concluded that the investigated values of EBRT result in similar values of RE i.e. a decrease of EBRT (corresponding to the increase of the gas flow rate) does not change the system performance for the investigated time period.

Effect of addition of $n$-butanol on the cyclohexane removal in the biotrickling filter is given in Fig. 3. The values of IL for both cyclohexane and $n$-butanol are given in Table 3. The pattern of IL variations is similar as discussed above when the removal of single cyclohexane was discussed (compare Fig. 2). Values of RE fluctuate during the stages I and II, due to variable IL as well as low accommodation of the microbes within the biofilter packed bed. It is interesting, however, that the removal efficiency drops in the late phase of a stage II (Figs. 2, 3). Such phenomenon is probably due to the high inlet loading of cyclohexane (Fig. 2) as well as of both cyclohexane and $n$-butanol (Fig. 3) and still incompletely developed biofilm. A drop of a biofilter performance for increased inlet loading was observed by Yang et al. (2003). Another reason for the drop of removal efficiency may be due to increased biomass growth result corresponding to increased inlet loading drops (Yang et al. 2010b). The biomass overgrowth may lead to bed clogging and channeling phenomenon, which results in deterioration in the biofilter performance. However, it is rather not the case in these investigations and a decrease of ILs for both $n$-butanol and cyclohexane at stage III results in an increase of RE values, up to about $90 \%$ at the 23 rd day of the biofiltration process. Values of RE stabilize during stages IV and V and the RE values are considerably higher (Fig. 3) than those presented in Fig. 2 when single cyclohexane was treated. This behavior of a system indicates that the addition of hydrophilic $n$-butanol
Fig. 2 Effects of IL and EBRT on the removal efficiency of cyclohexane in a peat-perlite biotrickling filter $\left(\mathrm{I}-\mathrm{IL}=45 \mathrm{~g} \mathrm{~m}^{-3} \mathrm{~h}^{-1}\right.$, II-IL $=112.5 \mathrm{~g} \mathrm{~m}^{-3} \mathrm{~h}^{-1}$, III-IL $=45 \mathrm{~g} \mathrm{~m}^{-3} \mathrm{~h}^{-1}$, $\mathrm{IV}-\mathrm{IL}=180 \mathrm{~g} \mathrm{~m}^{-3} \mathrm{~h}^{-1}, \mathrm{~V}-$ $\mathrm{IL}=144 \mathrm{~g} \mathrm{~m}^{-3} \mathrm{~h}^{-1}$, EBRT (I$\mathrm{IV})=60 \mathrm{~s}, \operatorname{EBRT}(\mathrm{V})=46 \mathrm{~s})$

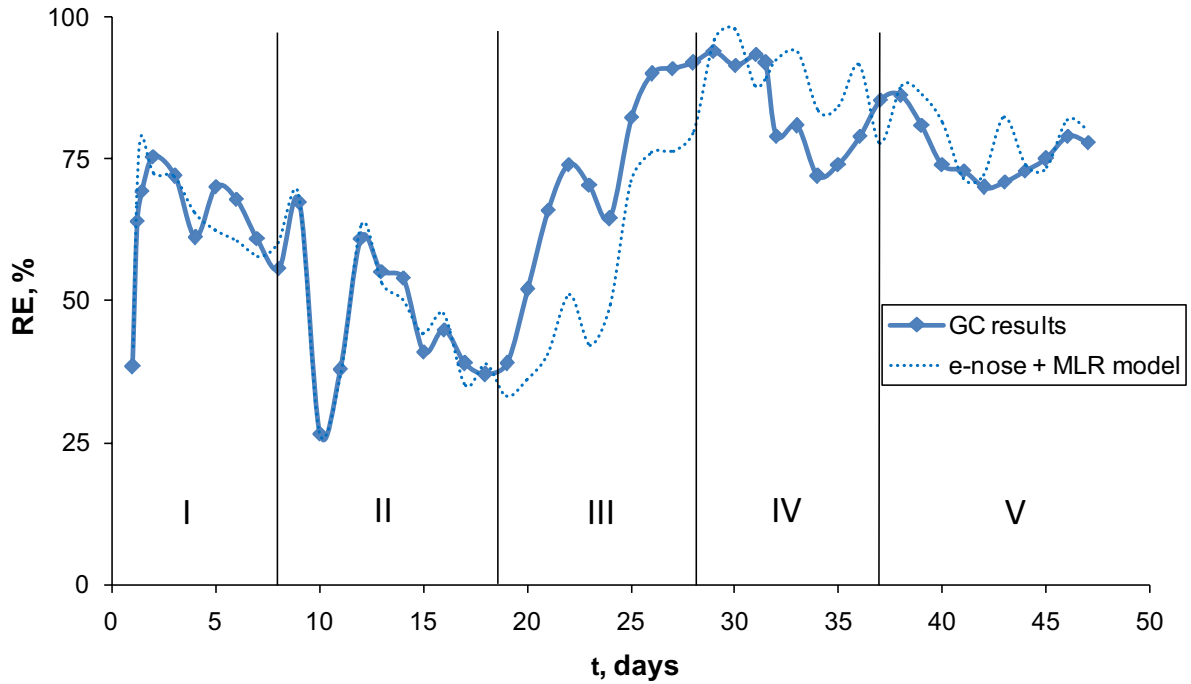


Fig. 3 Effect of addition of $n$-butanol on the performance of peat-perlite biotrickling filter treating air polluted with cyclohexane for various IL and EBRT values [EBRT (I$\mathrm{IV})=60 \mathrm{~s}, \operatorname{EBRT}(\mathrm{V})=46 \mathrm{~s}]$

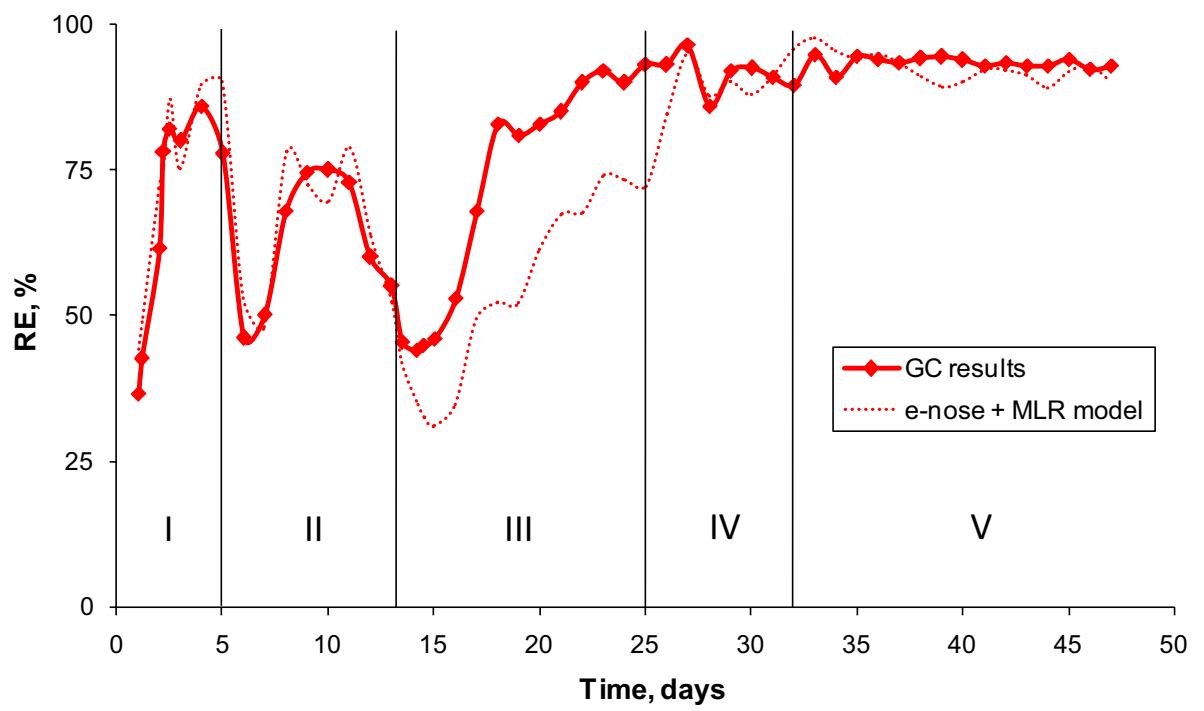

Table 3 Values of IL for stages I-V of cycclohexane biotrickling filtration in the presence of $n$-butanol (according to Fig. 3)

\begin{tabular}{llllll}
\hline Biofiltration stage & I & II & III & IV & V \\
\hline IL $\left(\mathrm{g} \mathrm{m}^{-3} \mathrm{~h}^{-1}\right)$ (cyclohexane) & 45 & 112.5 & 45 & 180 & 144 \\
IL $\left(\mathrm{g} \mathrm{m}^{-3} \mathrm{~h}^{-1}\right)(n$-butanol $)$ & 19.8 & 99 & 39.6 & 39.6 & 50.7 \\
\hline
\end{tabular}

results in an increased performance of a biotrickling filter treating hydrophobic cyclohexane. Possibility of such a behavior was discussed (Cheng et al. 2016a; Yang et al. 2018) and may be explained by an increase in bioavailability of hydrophobic VOCs for the biofilm resulting from the addition of a hydrophilic compound. It is important because the relatively low mass transfer rates from gas to the biofilm phase limit the biodegradation of hydrophobic compounds. The observed increase of removal efficiency of cyclohexane may also be a result of enhanced growth of microbes within the biofilm when $n$-butanol is fed to the biofilter and it seems to be an easily available source of carbon for the microbial species, due to its high solubility in water. Additionally, the microbial composition of the biofilm may get adjusted to the treated gas mixture, resulting in enhanced growth of species particularly involved in the biodegradation of cyclohexane and $n$-butanol. However, such investigations were not within the scope of this work and the explanation of mechanisms of synergistic interactions between the gas components should the objective in the future research regarding biotrickling filtration (Yang et al. 2018; Rybarczyk et al. 2019).

Effects of starvation episodes on the cyclohexane biotrickling filtration are presented in Figs. 4 and 5. Studies on the effect of starvation on the system performance are valuable when scaling up the biotrickling filtration is
Fig. 4 Effects of starvation periods on the removal efficiency of cyclohexane (IL $=144 \mathrm{~g} \mathrm{~m}^{-3} \mathrm{~h}^{-1}$, $\mathrm{EBRT}=46 \mathrm{~s}$, grey bars indicate starvation periods of 12,24 and $48 \mathrm{~h}$, respectively)

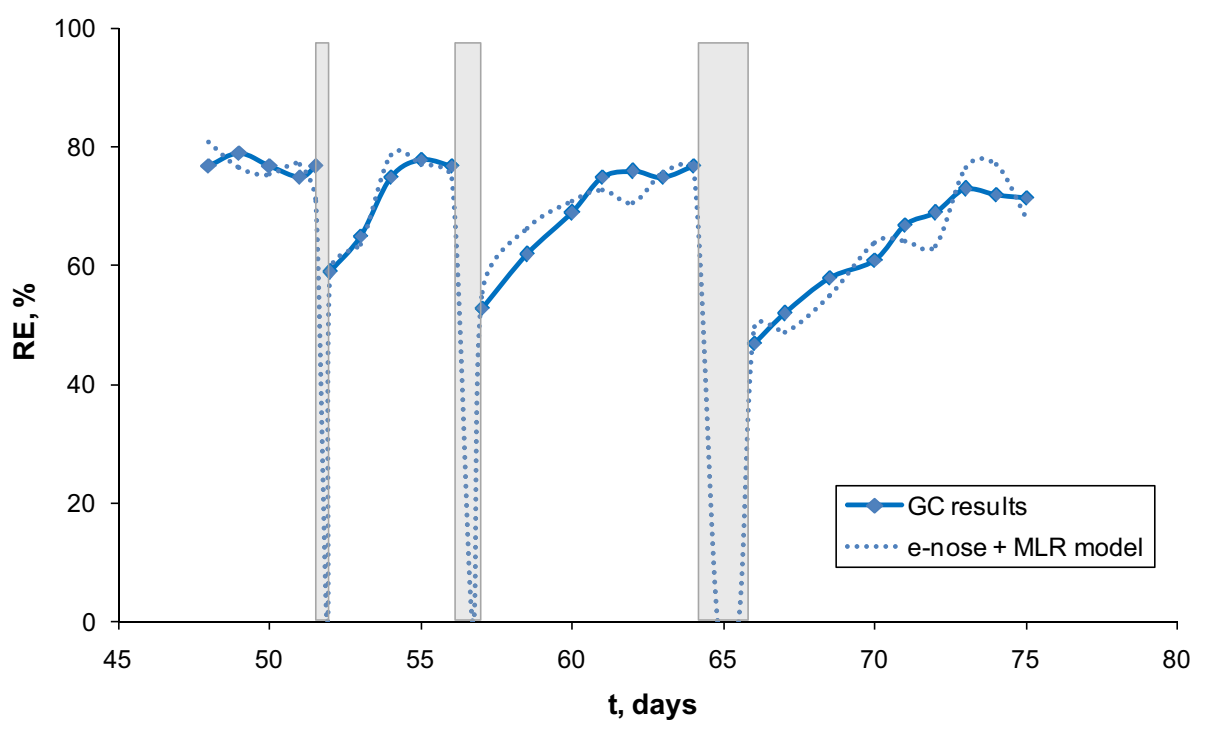


Fig. 5 Effects of starvation periods on the removal efficiency of cyclohexane treated in mixture with $n$-butanol [IL (cyclohexane) $=144 \mathrm{~g} \mathrm{~m}^{-3} \mathrm{~h}^{-1}$, IL $(n$-butanol $)=50.7 \mathrm{~g} \mathrm{~m}^{-3} \mathrm{~h}^{-1}$, $\mathrm{EBRT}=46 \mathrm{~s}$, grey bars indicate starvation periods of 12,24 and $48 \mathrm{~h}$, respectively]

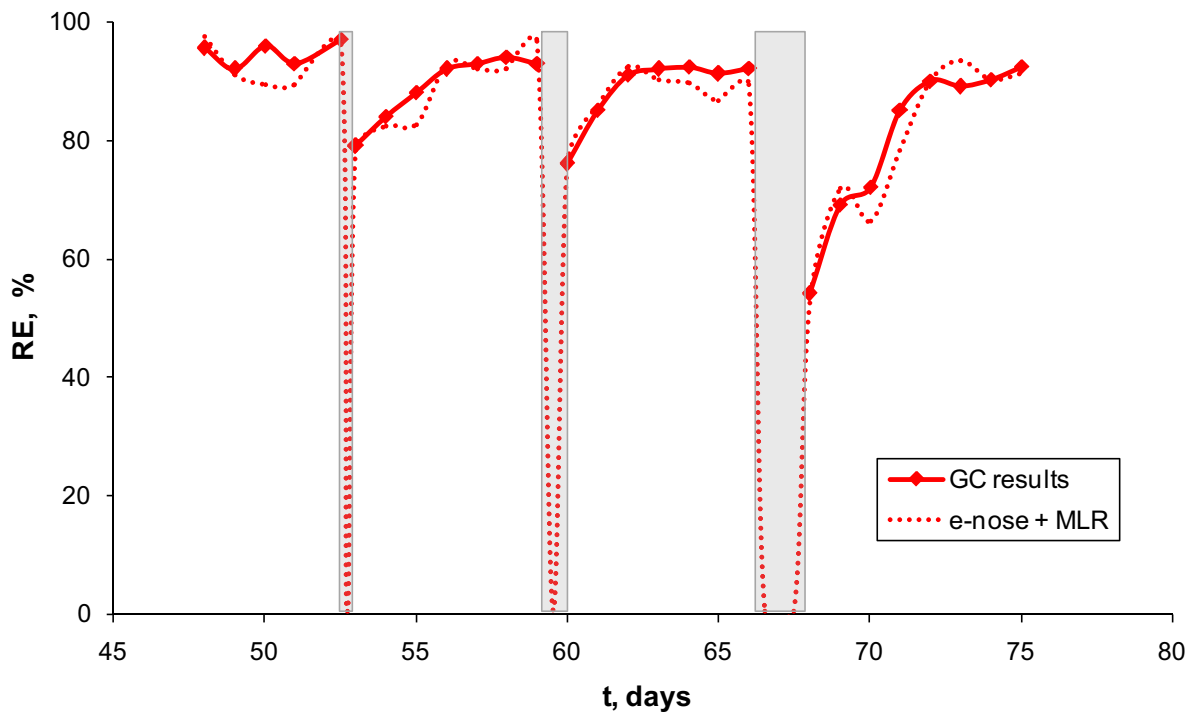

considered, because such events are common in the industrial practice.

In the discussed investigations, the starvation consisted in the elimination of cyclohexane or a mixture of cyclohexane and $n$-butanol from the inlet gas stream i.e. pure air was fed to the BTF during the starvation periods. The starvation events lasted for 12, 24 and $48 \mathrm{~h}$, and the subsequent starvation was introduced only when the system recovered to the performance similar to the one prior to the starvation, indicating the re-acclimation period (Cheng et al. 2016c). The starvation episodes were introduced when the investigated systems were working at steady-state conditions, i.e. around the day 50 from the processes start-up. The results presented in Figs. 4 and 5 show that the removal efficiency of cyclohexane is diminished as a consequence of starvation periods. The longer the starvation event, the higher the $\mathrm{RE}$ decrease and the longer the re-acclimation period. This observation is in accordance with the results obtained by Jiménez et al. (2017). What is more, the values of RE are slightly lower after each of the starvation episodes in both investigated systems (Figs. 4, 5). This may be a cause of a too short time between the episodes and an incomplete re-acclimation.

It must be noted that the biotrickling filtration performance is higher for the system treating cyclohexane with $n$-butanol as compared to the biotrickling filtration of cyclohexane only. Values of elimination capacity of cyclohexane reaching about $140-160 \mathrm{~g} \mathrm{~m}^{-3} \mathrm{~h}^{-1}$ were obtained in presented experiments. Such values of EC are typical for biofilters packed with organic materials (Miller et al. 2019), but considerably higher than EC of about $40 \mathrm{~g} \mathrm{~m}^{-3} \mathrm{~h}^{-1}$ obtained by Salamanca and co-workers (Salamanca et al. 2017). When cyclohexane was treated in the presence on $n$-butanol, the removal efficiency of $n$-butanol exceeded $90 \%$ for all investigated cases, corresponding to the EC of $n$-butanol reaching $50 \mathrm{~g} \mathrm{~m}^{-3} \mathrm{~h}^{-1}$. Similar elimination capacities were obtained by Schmidt et al. (2017) when $n$-butanol was removed from air in a co-current perlite-packed biotrickling filter, however, EC values reaching $1000 \mathrm{~g} \mathrm{~m}^{-3} \mathrm{~h}^{-1}$ are possible when biotrickling filtration of hydrophilic compounds is considered (Ramirez et al. 2007).

It is worth noting that the re-acclimation periods are shorter when cyclohexne is treated simultaneously with $n$-butanol, as given in Fig. 5 comparing to the results presented in Fig. 4. This observation supports the previous statement that the behavior and performance of a $\mathrm{BF}$ is enhanced when hydrophobic VOC is simultaneously treated with the hydrophilic one. Further research is proposed on the effects of starvation episodes on the BTF system performance, including also total starvation periods i.e. when air supply is stopped.

The use of electronic nose in the presented research allowed for easy automation of the assessment of the biofiltration process efficiency. In the case of analyzed volatile organic compounds (cyclohexane and $n$-butanol), the validity of the e-nose calibration using the MLR model was confirmed-during the studies of cyclohexane itself as well as with the addition of $n$-butanol, results comparable to gas chromatography analysis are obtained. Only during the third stage of biotrickling filtration (Figs. 2, 3), distinct differences were noticeable, which may be related to intermediate conditions between moderate and high inlet concentrations of cyclohexane, for the second and the fourth stage, respectively. Previous research confirmed that the proposed model underestimates the expected values of RE as compared to the gas chromatography results (Szulczyński et al. 2018). This fact may be caused by sensors saturation phenomenon and their transition to a nonlinear operating range. 


\section{Conclusions}

Investigations on the effects of basic process parameters (IL, EBRT), the addition of hydrophilic $n$-butanol and the starvation events on the biotrickling filtration of hydrophobic cyclohexane were presented and discussed in this paper. The results indicate that the removal efficiency of cyclohexane reaches the level of about $70-80 \%$ for the steady state conditions for an inlet loading of $144 \mathrm{~g} \mathrm{~m}^{-3} \mathrm{~h}^{-1}$ and the empty bed residence time of $46 \mathrm{~s}$. The removal efficiency of cyclohexane is much improved when it is treated in a mixture with $n$-butanol and values of cyclohexane removal efficiency reach more than $90 \%$ for the same values of IL and EBRT as given above. For the investigated range of EBRT values, the BTF system performance is kept constant, providing the steadystate conditions are reached. The results suggest the synergetic effects of $n$-butanol on the biotrickling filtration of cyclohexane supporting the hypothesis that hydrophilic VOCs may facilitate the biofiltration processes of hydrophobic VOCs. It was found that the longer the starvation periods, the longer the time needed to regain the initial removal performance of a biotrickling filter. Additionally, the biotrickling filter removal performance of cyclohexane is slightly diminished after each starvation period.

Results presented in this paper show the usefulness of application of the electronic nose for monitoring and evaluation of a biotrickling filtration process. It is suggested that such a device should be used for continuous monitoring of the process which may be especially valuable for the investigations of the process mechanisms and the system response to variable process conditions. It is proposed that future investigations in the field of basic research regarding the laboratory biotrickling filtration should focus on determining the mechanisms of mutual interactions of mixtures of various VOCs in the perspective of enhancing process efficiency by the composition of the treated gas stream. Additionally, such investigations should be related to changes in the microbial population of the biofilter and a search for new consortia specialized in effective treatment of multi-component gas mixtures.

Acknowledgements The investigations were financially supported by the Grant No. UMO-2015/19/B/ST4/02722 from the National Science Centre, Poland.

\section{Compliance with ethical standards}

Conflict of interests The Authors declare no conflict of interests.

Open Access This article is distributed under the terms of the Creative Commons Attribution 4.0 International License (http://creativeco mmons.org/licenses/by/4.0/), which permits unrestricted use, distribution, and reproduction in any medium, provided you give appropriate credit to the original author(s) and the source, provide a link to the Creative Commons license, and indicate if changes were made.

\section{References}

Barbusinski K, Kalemba K, Kasperczyk D, Urbaniec K, Kozik V (2017) Biological methods for odor treatment-a review. J Clean Prod 152:223-241. https://doi.org/10.1016/j.jclepro.2017.03.093

Cabeza IO, López R, Giraldez I, Stuetz RM, Diaz MJ (2013) Biofiltration of $\alpha$-pinene vapours using municipal solid waste (MSW) Pruning residues $(\mathrm{P})$ composts as packing materials. Chem Eng J 233:149-158. https://doi.org/10.1016/J.CEJ.2013.08.032

Chen H, Yang C, Zeng G, Luo S, Yu G (2012) Tubular biofilter for toluene removal under various organic loading rates and gas empty bed residence times. Bioresour Technol 121:199-204. https://doi. org/10.1016/j.biortech.2012.06.031

Cheng Y, He H, Yang C, Zeng G, Li X, Chen H, Yu G (2016a) Challenges and solutions for biofiltration of hydrophobic volatile organic compounds. Biotechnol Adv 34:1091-1102. https://doi. org/10.1016/j.biotechadv.2016.06.007

Cheng Y, He H, Yang C, Yan Z, Zeng G, Qian H (2016b) Effects of anionic surfactant on $n$-hexane removal in biofilters. Chemosphere 150:248-253. https://doi.org/10.1016/j.chemosphere.2016.02.027

Cheng Z, Lu L, Kennes C, Yu J, Chen J (2016c) Treatment of gaseous toluene in three biofilters inoculated with fungi/bacteria: microbial analysis, performance and starvation response. J Hazard Mater 303:83-93. https://doi.org/10.1016/j.jhazmat.2015.10.017

Gębicki J, Szulczyński B, Kamiński M (2015) Determination of authenticity of brand perfume using electronic nose prototypes. Meas Sci Technol 26:125103. https://doi.org/10.1088/09570233/26/12/125103

Gospodarek M, Rybarczyk P, Szulczyński B, Gębicki J (2019) Comparative evaluation of selected biological methods for the removal of hydrophilic and hydrophobic odorous VOCs from air. Processes 7:187. https://doi.org/10.3390/pr7040187

Guz Ł (2015) Zastosowanie matrycy półprzewodnikowych czujników gazu do ciągłego monitoringu poprawności procesu oczyszczania ścieków. Informatics Control Meas Econ Environ Prot 5:85-91. https://doi.org/10.5604/20830157.1176581 (in Polish)

Japan Chemical Industry Ecology-Toxicology \& Information Center, Japan, Chemicals Inspection \& Testing Institute (1992) Biodegradation and bioaccumulation data of existing chemicals based on the CSCL Japan. Japan Chemical Industry Ecology-Toxicology and Information Center, Tokyo

Jiménez L, Arriaga S, Muñoz R, Aizpuru A (2017) Effect of extended and daily short-term starvation/shut-down events on the performance of a biofilter treating toluene vapors. J Environ Manage 203:68-75. https://doi.org/10.1016/j.jenvman.2017.07.057

Lebrero R, Estrada JM, Muñoz R, Quijano G (2012) Toluene mass transfer characterization in a biotrickling filter. Biochem Eng J 60:44-49. https://doi.org/10.1016/j.bej.2011.09.017

McNevin D, Barford J (2000) Biofiltration as an odour abatement strategy. Biochem Eng J 5:231-242. https://doi.org/10.1016/S1369 $-703 \mathrm{X}(00) 00064-4$

Miller U, Sówka I, Adamiak W (2019) The effect of betaine on the removal of toluene by biofiltration. SN Appl Sci 1:984. https:// doi.org/10.1007/s42452-019-0832-6

Mirmohammadi M, Bayat R, Keshavarzi Shirazi H, Sotoudeheian S (2014) Effect of empty bed residence time on biotrickling filter performance: case study-triethylamine. Int J Environ Sci Technol 11:183-190. https://doi.org/10.1007/s13762-013-0382-1

Montebello AM, Bezerra T, Rovira R, Rago L, Lafuente J, Gamisans X, Campoy S, Baeza M, Gabriel D (2013) Operational aspects, pH transition and microbial shifts of a $\mathrm{H} 2 \mathrm{~S}$ desulfurizing biotrickling filter with random packing material. Chemosphere 93:2675-2682. https://doi.org/10.1016/j.chemosphere.2013.08.052

Montes M, Daugulis AJ, Veiga MC, Kennes C (2010) Removal of $\alpha$-pinene from waste gases in biotrickling filters with the addition 
of silicone oil or polymers. J Biotechnol 150:221. https://doi. org/10.1016/j.jbiotec.2010.09.048

Mudliar S, Giri B, Padoley K, Satpute D, Dixit R, Bhatt P, Pandey R, Juwarkar A, Vaidya A (2010) Bioreactors for treatment of VOCs and odours-a review. J Environ Manage 91:1039-1054. https:// doi.org/10.1016/j.jenvman.2010.01.006

Muñoz R, Daugulis AJ, Hernández M, Quijano G (2012) Recent advances in two-phase partitioning bioreactors for the treatment of volatile organic compounds. Biotechnol Adv 30:1707-1720. https://doi.org/10.1016/j.biotechadv.2012.08.009

Qian H, Cheng Y, Yang C, Wu S, Zeng G, Xi Y (2018) Performance and biofilm characteristics of biotrickling filters for ethylbenzene removal in the presence of saponins. Environ Sci Pollut Res 25:30021-30030. https://doi.org/10.1007/s11356-017-0776-6

Ramirez AA, Jones JP, Heitz M (2007) Biotrickling filtration of air contaminated with ethanol. J Chem Technol Biotechnol 82:329_ 333. https://doi.org/10.1002/jctb

Rene ER, Špačková R, Veiga MC, Kennes C (2010) Biofiltration of mixtures of gas-phase styrene and acetone with the fungus Sporothrix variecibatus. J Hazard Mater 184:204-214. https:// doi.org/10.1016/j.jhazmat.2010.08.024

Rybarczyk P, Szulczyński B, Gębicki J, Hupka J (2019) Treatment of malodorous air in biotrickling filters: a review. Biochem Eng J 141:146-162. https://doi.org/10.1016/j.bej.2018.10.014

Salamanca D, Dobslaw D, Engesser K-H (2017) Removal of cyclohexane gaseous emissions using a biotrickling filter system. Chemosphere 176:97-107. https://doi.org/10.1016/j.chemospher e.2017.02.078

Schiavon M, Ragazzi M, Rada EC, Torretta V (2016) Air pollution control through biotrickling filters: a review considering operational aspects and expected performance. Crit Rev Biotechnol 36:1143-1155. https://doi.org/10.3109/07388551.2015.1100586

Schmidt T, Anderson WA, Schmidt T, Anderson WA (2017) Biotrickling filtration of air contaminated with 1-butanol. Environments 4:57. https://doi.org/10.3390/environments4030057

Song T, Yang C, Zeng G, Yu G, Xu C (2012) Effect of surfactant on styrene removal from waste gas streams in biotrickling filters. J Chem Technol Biotechnol 87:785-790. https://doi.org/10.1002/ jctb. 3717

Szulczyński B, Wasilewski T, Wojnowski W, Majchrzak T, Dymerski T, Namieśnik J, Gębicki J (2017) Different ways to apply a measurement instrument of e-nose type to evaluate ambient air quality with respect to odour nuisance in a vicinity of municipal processing plants. Sensors (Switzerland) 17:2671. https://doi. org/10.3390/s17112671

Szulczyński B, Gębicki J, Namieśnik J (2018) Monitoring and efficiency assessment of biofilter air deodorization using electronic nose prototype. Chem Pap 72:527-532. https://doi.org/10.1007/ s11696-017-0310-9

Szulczyński B, Rybarczyk P, Gopodarek M, Gębicki J (2019) Biotrickling filtration of $n$-butanol vapors-process monitoring using electronic nose and artificial neural networks. Monatshefte für Chemie Chem Mon 150:1667-1673. https://doi.org/10.1017/ s00706-019-02456-w

Thormann MN, Rice AV (2007) Fungi from peatlands. Fungal Divers 24:241-299

Tu Y, Yang C, Cheng Y, Zeng G, Lu L, Wang L (2015) Effect of saponins on $n$-hexane removal in biotrickling filters. Bioresour Technol 175:231-238. https://doi.org/10.1016/j.biortech.2014.10.039

Vergara-Fernández A, Revah S, Moreno-Casas P, Scott F (2018) Biofiltration of volatile organic compounds using fungi and its conceptual and mathematical modeling. Biotechnol Adv 36:1079-1093. https://doi.org/10.1016/j.biotechadv.2018.03.008

Wu H, Yan H, Quan Y, Zhao H, Jiang N, Yin C (2018) Recent progress and perspectives in biotrickling filters for VOCs and odorous gases treatment. J Environ Manage 222:409-419. https://doi. org/10.1016/j.jenvman.2018.06.001

Yalkowsky SH, He Y (2010) Handbook of aqueous solubility data. CRC Press LLC, Boca Raton

Yang C, Suidan MT, Zhu X, Kim BJ (2003) Biomass accumulation patterns for removing volatile organic compounds in rotating drum biofilters. Water Sci Technol 48:89-96

Yang C, Chen F, Luo S, Xie G, Zeng G, Fan C (2010a) Effects of surfactants and salt on Henry's constant of $n$-hexane. J Hazard Mater 175:187-192. https://doi.org/10.1016/j.jhazmat.2009.09.147

Yang C, Chen H, Zeng G, Yu G, Luo S (2010b) Biomass accumulation and control strategies in gas biofiltration. Biotechnol Adv 28:531-540. https://doi.org/10.1016/j.biotechadv.2010.04.002

Yang B, Niu X, Ding C, Xu X, Liu D (2013) Performance of biotrickling filter inoculated with activated sludge for chlorobenzene removal. Procedia Environ Sci 18:391-396. https://doi. org/10.1016/j.proenv.2013.04.052

Yang C, Qian H, Li X, Cheng Y, He H, Zeng G, Xi J (2018) Simultaneous removal of multicomponent VOCs in biofilters. Trends Biotechnol 36:673-685. https://doi.org/10.1016/j.tibtech.2018.02.004

Publisher's Note Springer Nature remains neutral with regard to jurisdictional claims in published maps and institutional affiliations. 